\title{
Photoabsorption and energy band gap of amorphous Se alloy films
}

\author{
S C K MISRA $\dagger$ and T P SHARMA* \\ National Physical Laboratory, New Deihi 110 012, India \\ *Institute of Advanced Studies, Meerut University, Meerut 250004 , India \\ MS received 18 May 1990; revised 30 January 1991
}

\begin{abstract}
Amorphous selenium alloy films have been found to exhibit excellent photosensitive properties from 300 to $700 \mathrm{~nm}$. These films constitute the essential part of xerographic photoreceptors. Optical absorption, energy band gap and X-ray structural analysis of $\mathrm{Se}_{85} \mathrm{Te}_{15}$ and $\mathrm{Se}_{85} \mathrm{As}_{15}$ films are reported. The effect of annealing on these parameters has also been indicated.
\end{abstract}

Keywords. Photoabsorption; energy band gap; amorphous Se alloy films.

\section{Introduction}

Photosensitive devices mostly comprise of amorphous thin films, elemental or compound semiconductors like Si, CdS and Se or their alloys in various planar or MOS structure (Misra and Aggarwal 1971; Zallen 1983; Misra 1985; Mehendru and Misra 1986; Sharma et al 1989). The lattice ordering in Se thin films plays a dominant role in determining the characteristics and performance of the photosensitive device. The performance of the device depends on preparation conditions, the impurity content, the-film thickness and the post-deposition heattreatment etc. of the film (Lanyon 1964; Watanabe and Kao 1979; Vermaak and Petruzello 1982; Onozuka and Oda 1988). The optical transmission, absorption and electrical conductivity of the amorphous films are determined by the short-range atomic ordering of the lattice (Zallen et al 1971; Tauc 1974). In thin films, the local order and defect concentration control the conductivity and photoresponse; hence the photosensitive properties are affected by addition of impurities to the host material (Juhasz and Kasap 1985) as it causes perturbation in the local charge balance (Street and Mott 1975; Anderson 1977; Mott 1985; Mahadevan et al 1988). In the present paper we report the preparation, optical properties and structural analysis of amorphous films of Se with Te and As.

\section{Experimental}

Uniform composition Se-Te films can be prepared by vacuum evaporation of alloy materials (Chiba and Funakoshi 1988). The starting material was prepared by mixing Se and $\mathrm{Te}$ in proper composition by weight. The mixture was sealed in an evacuated quartz tube and heated at $500^{\circ} \mathrm{C}$ for $1 \mathrm{~h}$ along with the rotation of the quartz tube. The quartz ampoule was quenched in ice cold water to obtain the SeTe and Se-As alloy base materials. This quenched alloy was evaporated on to glass substrates held at room temperature in a vacuum of the order of $5 \times 10^{-6} \mathrm{~mm} \mathrm{Hg}$. The films thus grown had a thickness of the order of $5000 \AA$ (as determined by mass

† For correspondence. 
estimation of starting material and the deposited mass). The transmission and absorption spectra of the films in the range $300-2600 \mathrm{nms}$ were obtained by using Hitachi U-3400 computerised spectrophotometer. The energy band gap $E_{g}$ was calculated using the relation

$$
\alpha=\left(h v-E_{\beta}\right)^{1 / 2},
$$

where $\alpha$ is the absorption coefficient and $v$ the frequency of the incident radiation.

The X-ray diffraction data for the films were obtained and then chemical composition analysed by spectrochemical analysis and these agreed with that of the starting alloy to within $0 \cdot 1 \%$. The films were annealed in vacuum $\left(10^{-5} \mathrm{~mm} \mathrm{Hg}\right)$ at $70^{\circ} \mathrm{C}$ for $1 \mathrm{~h}$.

\section{Results and discussions}

The data for $\mathrm{Se}_{85} \mathrm{As}_{15}$ and $\mathrm{Se}_{85} \mathrm{Te}_{15}$ films are reported in this paper. Figure 1 shows the absorption spectra for unannealed and annealed films of $\mathrm{Se}_{85} \mathrm{As}_{15}$ and $\mathrm{Se}_{85} \mathrm{Te}_{15}$ in the 300 to $2600 \mathrm{~nm}$ wavelength region. Also included are the data for amorphous Se films (Misra 1985). Se films have a large absorption below $600 \mathrm{~nm}$ (curve 5, figure 1). Compared to that of Se, which has a sharp cut-off, the absorption of unannealed $\mathrm{Se}_{85} \mathrm{As}_{15}$ films (curve 1, figure 1) shows a high

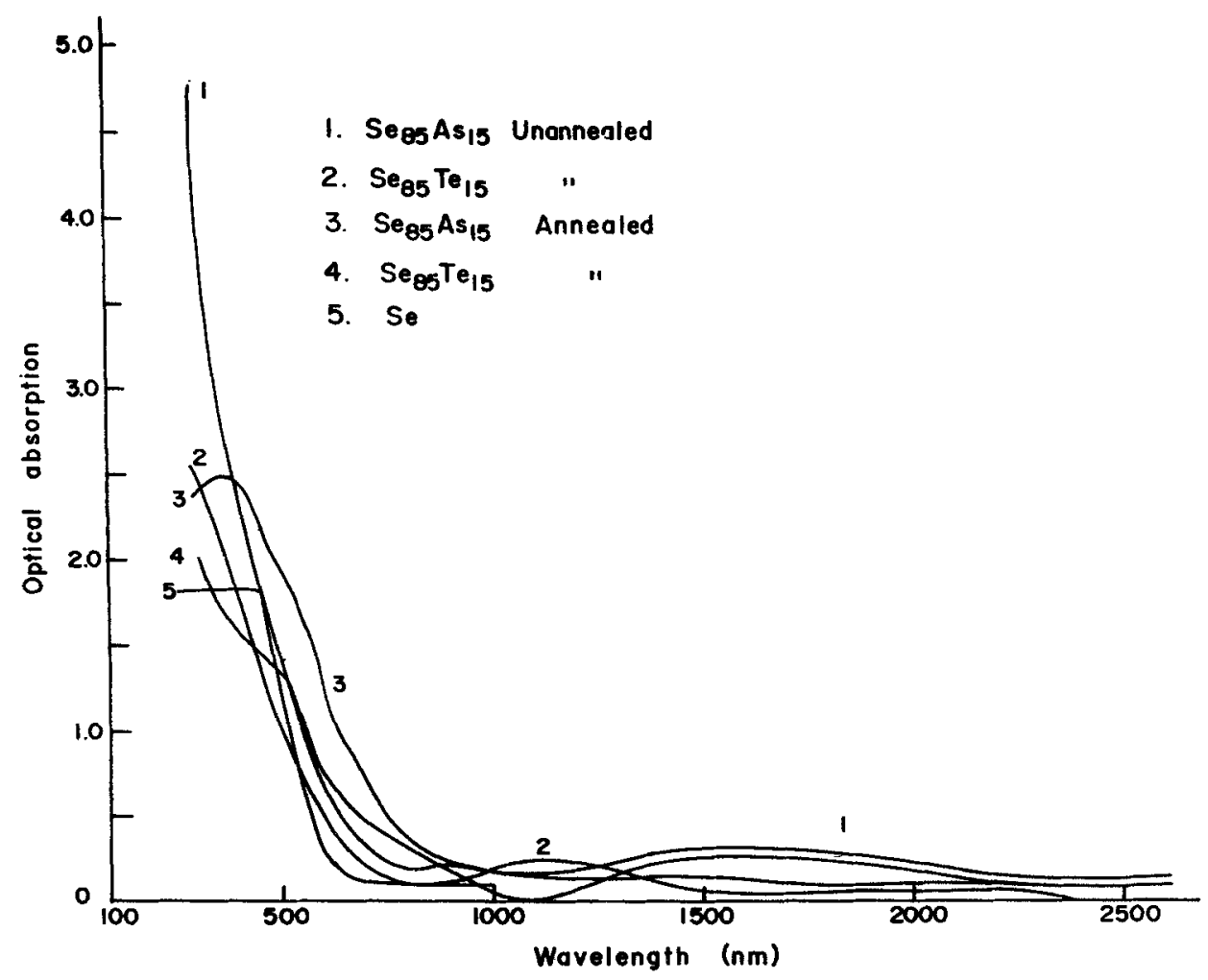

Figure 1. Optical absorption of $\mathrm{Se}_{85} \mathrm{As}_{15}$, and $\mathrm{Se}_{85} \mathrm{Te}_{15}$ alloy films in the wavelength range $300-2600 \mathrm{nms}$ before and after annealing and also of Se amorphous films. 
absorption below $500 \mathrm{~nm}$. On annealing (for $60 \mathrm{~min}$ at $70^{\circ} \mathrm{C}$ ) these films indicate a lower absorption in the 300 to $500 \mathrm{mn}$ region (curve 3, figure 1).

The data for unannealed and annealed films of $\mathrm{Se}_{85} \mathrm{Te}_{15}$ are depicted in curves 2 and 4 of figure 1 . They indicate a high absorption below $600 \mathrm{~nm}$. A peak which appears in the absorption spectra of as-deposited $\mathrm{Se}_{85} \mathrm{Te}_{15}$ films probably shifts to lower wavelength values on annealing.

Figure 2 shows the square of absorption as a function of photon energy for (a) unannealed and (b) annealed $\mathrm{Se}_{85} \mathrm{As}_{15}$ films. On annealing, a peak appears at about $4 \mathrm{eV}$ which is due to crystallization.

The X-ray diffractograms of unannealed and annealed $\mathrm{Se}_{85} \mathrm{As}_{15}$ films and of the annealed $\mathrm{Se}_{85} \mathrm{Te}_{15}$ films are shown in figure 3, traces (a), (b) and (c) respectively. These data were taken for films annealed for $10 \mathrm{~min}$ at $70^{\circ} \mathrm{C}$. Peaks due to formation of microcrystallites in an amorphous matrix are seen for the annealed films. Similar results are reported during annealing of InSe films (Sharma et al 1990).

Figure 4 shows the band gap energy vs annealing time for these films. The annealing temperature is $70^{\circ} \mathrm{C}$. The as-deposited films of Se, $\mathrm{Se}_{85} \mathrm{As}_{15}$ and $\mathrm{Se}_{85} \mathrm{Te} e_{\mathrm{is}}$ have band gap energies of $2.62,2.56$ and $2.30 \mathrm{eV}$ respectively. The effect of annealing is dominant within the first ten min. For $\mathrm{Se}_{85} \mathrm{As}_{15}$ films, the band gap reduces from $2.56 \mathrm{eV}$ to $2.47 \mathrm{eV}$ after annealing for $10 \mathrm{~min}$ and reduces to $2 \cdot 20 \mathrm{eV}$ for larger annealing times. For the $\mathrm{Se}_{85} \mathrm{Te}_{15}$ films, on the other hand, the band gap increases from 2.39 to $2.47 \mathrm{eV}$ in the first $10 \mathrm{~min}$ and increases to $2.65 \mathrm{eV}$ on further annealing. In the case of Se, the band gap reduces from $2.62 \mathrm{eV}$ to $1.70 \mathrm{eV}$ on annealing. Thus, annealing of $\mathrm{Se}_{85} \mathrm{Te}_{15}$ films renders these films more insulating compared to those of $\mathrm{Se}_{85} \mathrm{As}_{15}$ films, which become more conducting on annealing. Similar results have been reported for As-Se halide and Ge-Se glasses (Napo et al 1988; Sanghera et al 1988).

\section{Conclusion}

Amorphous film of Se with Te and As can be prepared by vacuum evaporation of

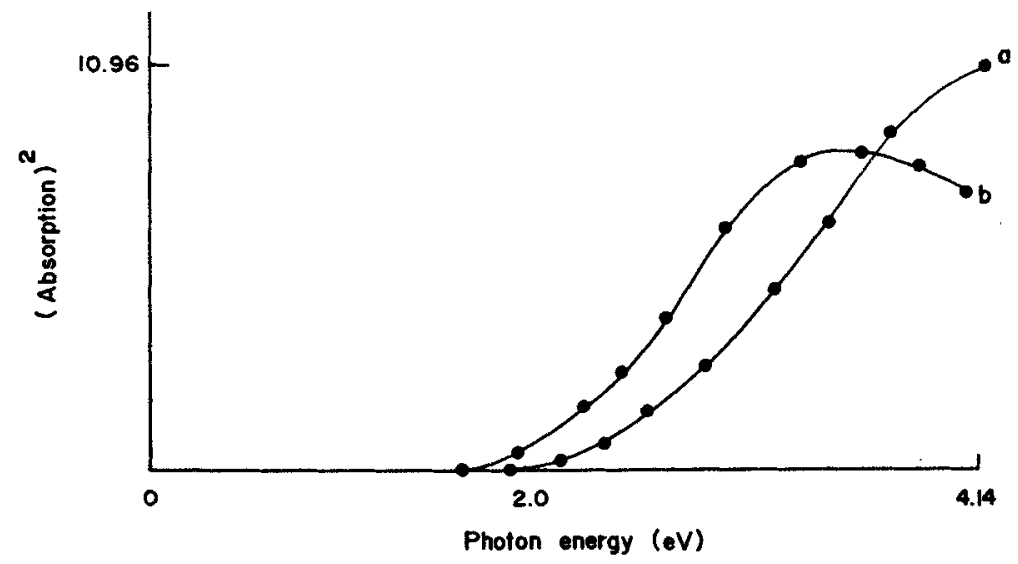

Figure 2. Variation of the square of optical absorption with photon energy for (a) unannealed and (b) annealed $\mathrm{Se}_{85} \mathrm{As}_{15}$ films. 


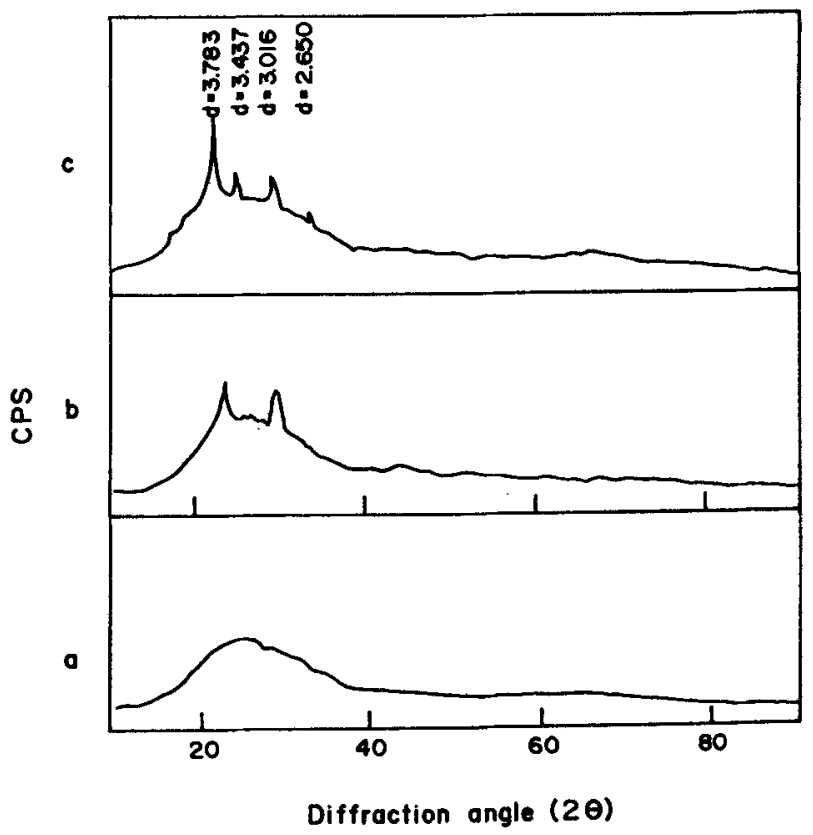

Figure 3. X-ray diffractogram of $\mathrm{Se}_{85} \mathrm{As}_{15}$ films. a. unannealed, b. annealed, (for $10 \mathrm{~min}$ at $70^{\circ} \mathrm{C}$ ) and c. annealed $\mathrm{Se}_{85} \mathrm{Te}_{15}$ films (for $10 \mathrm{~min}$ at $70^{\circ} \mathrm{C}$ ).

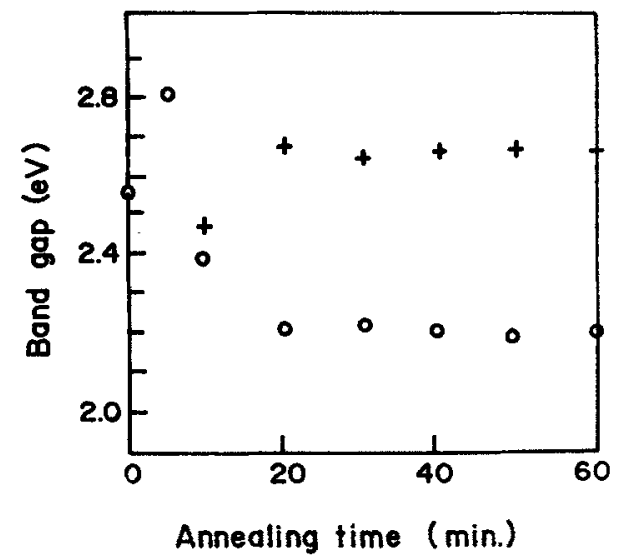

Figure 4. Variation of the energy band gap of the $\mathrm{Se}, \mathrm{Se}_{85} \mathrm{As}_{15}$ and $\mathrm{Se}_{85} \mathrm{Te}_{15}$ alloy films, with duration of annealing.

the base materials. The alloy films of Se with Te and As have advantage over pure amorphous $\mathrm{Se}$ in their modified optical absorption, electrical conductivity and variable energy band gap, depending upon the composition of the alloy materials. The optical absorption of $\mathrm{Se}_{85} \mathrm{Te}_{15}$ and $\mathrm{Se}_{85} \mathrm{As}_{15}$ extends over a wide range of wavelengths yielding an improved photosensitivity. Annealing of the films modifies the optical absorption, energy band gap and electrical conductivity and induces crystallization of the alloy films. Efficient photoreceptors can be prepared by using the appropriate composition, annealing temperature time and film thickness. 


\section{Acknowledgements}

The authors thank Dr Subhas Chandra, for stimulating discussions.

\section{References}

Anderson P W 1977 Phys. Rev. B16 420

Chiba R and Funakoshi N 1988 Thin Solid Films 157307

Damodar Das V and Jansilaxmi P 1988 J. Mater. Sci. 233869

Juhasz C and Kasap S O 1985 J. Phys. D18 721

Lanyon H P D 1964 J. Appl. Phys. 351616

Mahadevan S, Giridhar A and Singh A K 1988 J. Non-Cryst. Solids 3155

Mehendru P C and Misra S C K 1986 Indian J. Technol. 24576

Misra S C K and Aggarwal Y K 1971 Res. Ind. 16260

Misra S C K 1985 Indian J. Pure Appl. Phys. 2378

Misra S C K, Sharma T P, Sharma S K, Kumar R and Jain G 1990 Indian J. Technol. 28205

Mott N F 1985 Contemp. Phys. 26203

Napo K, Bernede J C, Safoula G, Burgand P and Aneriziani A 1988 Thin Solid Films 157291

Onozuka A and Oda O 1988 J. Non-cryst. Solids 1.03289

Sanghera J S, Heo J and Mackenzie J D 1988 J. Non-cryst. Solids 103155

Sharma D C, Misra S C K, Kamalasanan M N and Chand S 1989 Indian J. Pure Appl. Phys. 2353

Sharma T P, Sharma S K, Kumar R, Jain G and Misra S C K 1990 Indian J. Pure Appl. Phys. 28486

Street R A and Mott N F 1975 Phys. Rev. Lett. 351293

Tauc $\mathrm{J} 1974$ in Amorphous and liquid semiconductors (London: Plenum)

Vermaak J S and Petruzello J 1982 J. Appl. Phys. 536809

Watanabe H and Kao K C 1979 Jap. J. Appl. Phys. 181849

Zallen R 1983 Physics of amorphous solids (New York: John Wiley)

Zallen R, Drews R E, Emerald R L and Slade M L 1971 Phys. Rev. Lett. 261564 